\title{
The Examination of Physical Education and Sport Students' Depth of Content Knowledge
}

\section{Beden Eğitimi ve Spor Bölümlerindeki Öğrencilerin Alan Bilgisi Düzeylerinin Belirlenmesi}

\section{Erhan Devrilmez (iD) https://orcid.org/0000-0002-5136-7510}

School of Physical Education and Sport, Karamanoğlu Mehmetbey University, Karaman, Turkey

\section{Fatih Dervent $\quad$ (iD) https://orcid.org/0000-0002-2612-3549 \\ Faculty of Sport Sciences, Marmara University, İstanbul, Turkey}

Received: December 6, $2018 \quad$ Accepted: March 20, $2019 \quad$ Online Published: March 31, 2019

DOl: 10.30655/besad.2019.14 https://doi.org/10.30655/besad.2019.14

\begin{abstract}
Effective teaching requires consistency between teachers' goals and students' learning outcomes. Content knowledge is one of the important knowledge bases for effective teaching. Content knowledge constitutes two sub-domains which are common content knowledge (CCK) and specialized content knowledge (SCK). The purpose of this study was to examine the depth of gymnastics content knowledge of students enrolled in physical education teacher education, sport management and coaching education departments. Participants were 32 coaching education, 36 sport management and 48 physical education teacher education, totally 116 students. To measure the depth of CCK of participants, gymnastics CCK test was utilized. Content maps were used for measuring participants' depth of SCK. Descriptive statistics and ANOVA were used for statistical calculations. Results showed that CCK scores of three groups were lower than expected value (at least 70\% correct answers). The physical education teacher education students' mean SCK score was higher than the benchmark (3.0 or over) that distinguishes between deeper and shallower content knowledge. Sport management and coaching education students did not reach the benchmark score. ANOVA results indicated that physical education teacher education students' CCK and SCK levels significantly better than coaching education and sport management students. Findings demonstrate that CCK and SCK can and should be saliently taught to teachers.
\end{abstract}

Key Words: Common content knowledge, Specialized content knowledge, Gymnastic, Physical education departments

\section{${ }^{1}$ Corresponding author: Erhan Devrilmez}

Karamanoğlu Mehmetbey Üniversitesi, Beden Eğitimi ve Spor Yüksekokulu, Yunus Emre Yerleşkesi, Karaman erhandevrilmez@kmu.edu.tr. 


\section{Öz}

Etkili ögrretim için öğretmenlerin hedefleri ile öğrencilerin öğrenme düzeyleri arasında bir uyum gerekmektedir. Etkili öğretim için gerekli temel bilgilerden biri alan bilgisidir. Alan bilgisi, genel alan bilgisi (GAB) ve özelleşmiş alan bilgisi (ÖAB) olarak iki alt boyuttan oluşmaktadır. Bu çalışmanın amacı, beden eğitimi ve spor yüksekokulları ile spor bilimleri fakültelerinin farklı bölümlerindeki öğrencilerin cimnastik alan bilgisi düzeylerinin incelenmesidir. Çalışmaya 32 antrenörlük, 36 spor yöneticiliği ve 48 beden eğitimi öğretmenliği bölümünden toplam 116 öğrenci katılmıştır. Katılımcıların GAB düzeylerini ölçmek için cimnastik genel alan bilgisi testi ve özelleşmiş alan bilgisi için içerik haritası kullanılmıştır. Verilerin analizinde tanımlayıcı istatistik ve ANOVA testleri kullanılmıştır. Bulgulara göre çalışmaya katılan üç grubun GAB skorları, beklenen başarı oranını (toplam soruların \%70 ya da üzeri doğru cevap) yakalayamamış görünmektedir. Beden eğitimi öğretmenliği bölümü öğrencilerinin özelleşmiş alan bilgisi bulguları etkili öğretmenlik için belirlenen kritik değerin (3.0) üzerinde bulunurken, spor yöneticiliği ve antrenörlük bölümleri öğrencileri istenen seviyeye ulaşamamıştır. ANOVA bulgularına göre beden eğitimi öğretmenliği bölümü öğrencilerinin genel ve özelleşmiş alan bilgi değerlerinin anlamlı olarak diğer bölümlerdeki öğrencilerden yüksek olduğu tespit edilmiştir. Sonuç olarak, alan bilgisinin alt boyutları olan genel ve özelleşmiş alan bilgilerinin ayrı ayrı öğretilmesinin önemli olduğu düşünülmektedir.

Anahtar kelimeler: Genel alan bilgisi, Özelleşmiş alan bilgisi, Cimnastik, Beden eğitimi bölümleri

\section{Giriş}

Öğretmek, öğrencilerin öğrenme sürecinde intiyaç duyduğu olanakları sağlamak olarak tanımlanmaktadır (Atkins \& Brown, 2002; Ellis, 2018). Etkili öğretimde öğretmenlerin hedefleri ile öğrencilerin öğrenme düzeyleri arasında bir uyum söz konusuyken etkisiz öğretimde öğrencilerin konu alanı ile ilgili öğrenme düzeylerini geliştiremedikleri görülür (Marsh, 1982; Siedentop, 2002). Shulman (1987) öğretmenlerin etkili öğretim gerçekleştirebilmesi için bazı temel bilgilere sahip olması gerektiğini belirtmiş̧ir. Bu temel bilgiler alan bilgisi, genel pedagoji bilgisi, müfredat bilgisi, pedagojik alan bilgisi, öğrenen bilgisi, eğitsel ortam bilgisi ve eğitsel çıktılar bilgisidir.

Alan bilgisi, Shulman'ın (1987) etkili öğretim için gerekli bilgi temellerinden biridir. Alanyazında öğretmenlerin belirli bir konu alanını öğretebilmek için sahip olması gereken bilgi olarak açıklanmaktadır (Grossman, 1990; Shulman, 1986; 1987). Beden eğitimi alanında yapılan çalışmalar, yeterli ve derin alan bilgisine sahip olmayan beden eğitimi öğretmenlerinin okul beden eğitimi derslerinde zengin öğrenme fırsatları oluşturamayan kısa süreli öğretimsel uygulamalar gerçekleştirdiğini göstermektedir (Rovegno, 1993; Siedentop, 2002). Dersinde futbol öğreten bir beden eğitimi öğretmeninin ayak içi pasın kritik elemanlarını gösterdikten sonra teknik gelişim odaklı öğrenme görevini öğrencilerine belirli bir süre uygulatıp sonrasında doğrudan maç yaptırması, ayak içi pasın kısa süreli öğretimine örnek olarak verilebilir. Bu durum öğrencilerin beklenen öğrenme çıktılarına ulaşamamasına neden olmaktadır. Alan bilgisi istendik seviyede olmayan öğretmenler, ilgili dersin öğretimsel becerilerini aynı öğrenme görevlerinde tekrar tekrar öğrettiklerinden öğrenciler öğrenme kazanımlarını edinememektedirler (Hastie \& Vlaisavljevic, 1999).

Alan bilgisi, uzun yıllardır üzerinde çalışıımasına rağmen içeriği ve kavramsallaştırılması konusunda tartışma devam etmektedir. Ball, Thames ve Phelps (2008) matematik alanındaki alan bilgisi kavramını iki alt boyutta incelemiştir. Genel alan bilgisi (GAB), bir öğretmenin neyi öğreteceğini bilmesidir. Özelleşmiş alan bilgisi (ÖAB) ise GAB'nin nasıl öğretileceğini bilmektir. GAB ve ÖAB kavramları, Ward (2009) tarafından beden eğitimi alanına aktarılmıştır. GAB, kurallar ve teknik-taktik bilgisi alt 
boyutlarından, ÖAB ise öğrenci hataları ve öğretim tasarımı ve sunumu alt boyutlarından oluşmaktadır. Bir beden eğitimi öğretmeninin yeterli ve derin alan bilgisine sahip olabilmesi için her iki alt boyutta da yeterli bilgiye sahip olması gerekmektedir (Ward, 2009).

Son zamanlarda yapılan deneysel çalışmalarda ÖAB derinliğini artan beden eğitimi öğretmenlerinin pedagojik alan bilgilerinin arttığı görülmüştür (Iserbyt, Ward, \& Coolkens, 2018; Iserbyt, Ward, \& Li, 2017; Iserbyt, Ward, \& Martens, 2015; Kim vd., 2018; Sinelnikov, Kim, Ward, Curtner-Smith, \& Li, 2016; Ward, Kim, Ko, \& Li, 2015). Pedagojik alan bilgisi, bir öğretmenin belirli bir konu alanını öğrencileri için daha anlaşılır hale getirmekte kullandığı öğretimsel uygulamalar ve düzenlemeler olarak tanımlanmaktadır (Shulman, 1986; Tanışlı, 2013). Pedagojik alan bilgisi etkili öğretmenlik için olmazsa olmaz bilgidir ve ÖAB ile doğrudan ilişkilidir (Iserbyt vd., 2018; Iserbyt vd., 2017; Iserbyt vd., 2015; Kim, 2015).

Milli Eğitim Bakanlığı Öğretmenlik Mesleği Genel Alan Yeterlikleri ilk maddesi (A1) 'alanında sorgulayıcı bakış açısını kapsayacak şekilde ileri düzeyde kuramsal, metodolojik ve olgusal bilgiye sahiptir' (2017, s. 8) olarak ifade edilmiştir. Bu ifade öğretmen yeterlikleri açısından alan bilgisinin önemini vurguladığı için değerlidir. Uluslararası eğitim kuruluşları da alan bilgisinin önemini yansıtan benzer standartlara sahiptir. Örneğin; Amerika Sağlık ve Beden Eğitimciler Topluluğu (Society of Health and Physical Educators America [SHAPE America], 2017) beden eğitimi öğretmen yetiştirme programları standartlarında (Standart 1.1 ve 1.2) GAB ve ÖAB'ni öğretmen adaylarının sahip olması ve uygulaması gereken bilgiler olarak sınıflamıştır. Aynı zamanda; Amerikan Eğitsel Test Hizmetleri de (Educational Testing Service [ETS], 2012) öğretmenlik mesleki bilgi değerlendirme sınavlarında kullanılan soruların öğretmenlerin uygulamalarında sundukları öğrenme görevleri ve genel öğrenci hatalarını içeren ÖAB'yle ilişkili olarak hazırlandığını belirtmektedir. Türkiye'de güncellenerek 2018/2019 yılında itibaren okutulan beden eğitimi ve spor öğretmenliği lisans programı önceki programın aksine (YÖK, 1998) sadece GAB'ne odaklanmayla kalmayıp ÖAB'ni de vurgu yapmaktadır. Yeni programın fiziksel aktivite ve spor derslerinde (atletizm, takım sporları, cimnastik vb.) örneğin; cimnastik ders içeriğinin tanımlandığı bölümün sonunda 'hata tespiti ve öğretim bilgisi' ifadeleri okunduğunda bu vurgu görülebilir(Yüksek Öğrenim Kurumu, 2018).

Ülkemizdeki beden eğitimi ve spor yüksekokullarında ya da spor bilimleri fakültelerinde beden eğitimi ve spor öğretmenliği, spor yöneticiliği, antrenörlük eğitimi ve rekreasyon bölümleri bulunmaktadır (Başbakanlık Devlet Planlama Teşkilatı Müsteşarlığı, 2000; Turgut, Gökyürek, \& Yenel, 2004). Her bölümün ayrı müfredatı ve amaçları bulunmaktadır. Müfredat ve öğrencilerden beklenen çıktılardaki farklııklar, bölümlerde fiziksel aktivite ve spor derslerini yürüten öğretim elemanlarının ders işleyişlerinde farklılaşmalara neden olmaktadır. Fiziksel aktivite ve spor derslerindeki uygulamaların beden eğitimi ve spor bölümlerindeki öğrencilerin alan bilgisi düzeyini etkileyip etkilemediğini inceleyen çalışma sayısı alan yazında yeterli sayıda değildir. Az sayıda çalışmalardan biri Ward, Tsuda, Dervent ve Devrilmez (2018) tarafından gerçekleştirilmiştir. Çalışmada GAB odaklı grup ile ÖAB odaklı grup karşılaştırmış ve farklı uygulamaları olan grupların alan bilgisi alt boyutlarındaki bilgi düzeylerinde farklılaşma bulunmuştur. Alan bilgisinin GAB ve ÖAB alt boyutlarına odaklanan çalışmalar alan yazında bulunmasına rağmen beden eğitimi ve spor yükseköğrenimi veren kurumların farklı bölümlerindeki öğrencilerin alan bilgisini inceleyen çalışma sayısı yeterli değildir. Bu çalışmanın amacı, beden eğitimi ve spor yüksekokulları ile spor bilimleri fakültelerinin farklı bölümlerindeki öğrencilerin cimnastik alan bilgisi düzeylerinin incelenmesidir. 


\section{Yöntem}

Çalışma için bir devlet üniversitesinden gerekli etik kurul izni alınmıştır. Ayrıca her katılımcı gönüllü katıım formunu imzalamıştır.

\section{Katılımcılar}

Çalışmaya 32 antrenörlük bölümü (27 erkek ve 5 kadın), 36 spor yöneticiliği bölümü (21 erkek ve 15 kadın) ve 48 beden eğitimi öğretmenliği bölümü (26 erkek ve 22 kadın) öğrencisi katılmıştır. Katılımcıların yaş ortalaması antrenörlük bölümü için 18.74 (SS=1.55), spor yöneticiliği için 19.63 (SS= 1.12) ve beden eğitimi öğretmenliği için 19.21 (SS= 1.82) olarak belirlenmiştir. Beden eğitimi öğretmenliği bölümünden iki katıımcı, küçük yaş gruplarında yaklaşık iki yıldır antrenörlük yapmaktadır. Diğer katıımcıların tamamı cimnastik sporu ile ilgili sporculuk ya da antrenörlük deneyimine sahip olmadıklarını belirtmişlerdir.

\section{Araştırma Tasarımı}

$\mathrm{Bu}$ çalışmada nicel araştırma desenlerinden nedensel-karşılaştırma deseni kullanılmıştır. Nedensel-karşılaştırma deseni, mevcut olan gruplar arasındaki farklılıkların sebeplerini ve sonuçlarını incelemeyi amaçlar (Fraenkel, Wallen, \& Hyun, 2012). Çalışmada beden eğitimi öğretmenliği, spor yöneticiliği ve antrenörlük bölümlerindeki öğrencilerin tamamlanan cimnastik dersi sonunda cimnastik alan bilgisi farkları incelenmiştir.

\section{Cimnastik Dersi Öğretim Elemanları}

Beden eğitimi öğretmenliği bölümünde cimnastik dersini yürüten öğretim elemanı son iki yıldır cimnastik öğretimi gerçekleştiren 39 yaşında doktoralı erkek bir öğretim elemanıdır. Spor yöneticiliği bölümü dersini gerçekleştiren öğretim elemanı 55 yaşında yüksek lisans mezunu ve yaklaşık 15 yıldır beden eğitimi ve spor bölümlerinde cimnastik derslerini yürütmektedir. Antrenörlük bölümünde cimnastik dersini uygulayan öğretim elemanı 40 yaşında doktoralı ve yaklaşık 15 yıldır cimnastik sporu ile ilgilenmekte ve altı yıldır beden eğitimi ve spor bölümlerinde cimnastik dersini yürütmektedir.

\section{Veri Toplama Araçları}

Bu bölümde araştırmanın verilerinin elde edilmesinde kullanılan ölçme araçlarına yönelik bilgiler aktarılmıştır.

\section{Genel Alan Bilgisi Testi}

Katılımcıların GAB düzeylerini ölçmek için Devrilmez, Dervent, Ward ve Ince (Basımda) tarafından geliştirilen 19 soruluk çoktan seçmeli Cimnastik GAB testi kullanılmıştır. GAB testinde kurallar için 6 soru ve teknik için 13 soru yer almaktadır. Cimnastik sporunun doğası gereği taktik boyutunu ölçmeye yönelik soru yer almamaktadır. Testin güvenirliği. 94 olarak tespit edilmiş ve testte yer alan tüm soruların uyum indeksleri yüksek bulunmuştur. Bilgi testlerinde katılımcıların başarılı kabul edilebilmesi için testte yer alan toplam soruların \%70 veya üzerinde doğru cevaba sahip olması gerekmektedir (Castelli \& Williams, 2007; South Carolina Department of Education [SDE], 2000). 


\section{İçerik Haritası}

Çalışmada yer alan öğrencilerin ÖAB düzeyini belirlemek için Ward ve arkadaşları (2017) tarafından geçerliği ve güvenirliği kanıtlanan içerik haritası kullanılmıştır. İçerik haritası, katılımcıların bir beden eğitimi dersinde öğretilmesi amaçlanan becerilerin/tekniklerin gösterilmesidir. İçerik haritası doldurulmadan önce boş bir sayfadır ve katıımcı önce öğretmeyi planladığı becerileri/teknikleri sayfanın en altına yatay olarak soldan sağa yazar (basketbolda top sürme, pas vb.). ilk aşamayı tamamladıktan sonra altta yer alan her beceri/teknik için aşağıdan yukarıya doğru öğretim basamaklamasındaki adımları kısa ifadelerle yazarak belirtir (1'e o top sürme).Son olarak yukarı doğru belirtilen beceriler/teknikler birbirleriyle eşleştirilerek (basketbolda $3 \vee 1$ top sürme ve sıçrayarak şut) farklı kombinasyonlar yapılabilir. İçerik haritası tamamlandığında, katıımcının ÖAB düzeyini belirlemek, etkili ve etkisiz öğretim arasındaki farklııkları ortaya koymak için geçerli ve güvenilir bir ölçme aracıdır (Ward vd., 2017). İçerik haritası için daha ayrıntılı bilgilendirme ve örneklere https://www.youtube.com /watch?v=i CE7CEa7KPU\&t=28s adresinden ulaşılabilir.

\section{Öğretim Tasarımı Geliştirme Kategorileri}

Içerik haritalarında ÖAB derinliğini analiz edebilmek için Rink (1979) tarafından geliştirilmiş dört alt boyutlu öğretim tasarımı geliştirme kategorilerinin uyarlanmış hali kullanılmıştır. Ward ve arkadaşları (2017) bu kategorileri Taktiksel Oyun Modeli (Mitchell, Oslin, \& Griffin, 2013)ve Oyun Uygulamaları Modeli gibi (Launder \& Piltz, 2013) beden eğitimine özgü bazı pedagojik modellerde kullanılan öğretim tasarımlarına uygun hale getirmek için bazı uyarlamalar gerçekleştirmiştir. Uyarlanan yeni öğretim tasarımı geliştirme kategorileri tablo 1'de açıklanmıştır. Kategoriler, içerik haritasında belirtilen öğretim tasarımlarının kodlanması ve formüle edilmesini sağlamaktadır.

Tablo 1. Öğretim Tasarımı Geliştirme Kategorileri

\begin{tabular}{l|l}
\hline Kategoriler & \multicolumn{1}{c}{ Açıklama } \\
\hline Bilgilendirme (BI) & $\begin{array}{l}\text { Bir becerinin öğretim basamaklamasındaki ilk öğretilen tasarımıdır } \\
\text { ve diğer öğretim tasarımı kategorileriyle birlikte değerlendirimez. } \\
\text { Örneğin, "basketbolda karşılıklı paslaşma ile derse başlayalım" diye } \\
\text { belirtilen ilköğretim tasarımı. }\end{array}$ \\
\hline Basamaklama (BA) & $\begin{array}{l}\text { Önceki öğretim tasarımının zorlaştırıması için öğe eklenmesi } \\
\text { (parçadan bütüne), değiştirilmesi ya da yeni boyut eklenmesi (yer, } \\
\text { mesafe, hız, amaç ve alan gibi) ya da daha fazla çeşitlilik eklenmesi } \\
\text { (öğrencilerin farklı yönlere hareket etmesini istemek gibi). Örneğin; } \\
\text { futbolda paslaşmayı daha uzun mesafede yapmak ya da } \\
\text { paslaşmayı 3'e 1 yapmak için önceki öğretim tasarımına savunma } \\
\text { oyuncusu eklemek. }\end{array}$ \\
\hline iyileştirme (IY) & $\begin{array}{l}\text { Teknik ya da taktik performansın kalitesinin arttırımasına } \\
\text { odaklanılan öğretim tasarımıdır. Örneğin; cimnastikte düz takla } \\
\text { öğretiminde öne yuvarlanırken çenesini göğsüne yaslayamayan } \\
\text { öğrencinin çenesinin altına küçü bir sünger parçası koyup } \\
\text { yuvarlanma esnasında taşımasını istemek. }\end{array}$ \\
\hline
\end{tabular}




\begin{tabular}{l|l}
\hline $\begin{array}{l}\text { Uygulamada } \\
\text { Basamaklama (UB) }\end{array}$ & $\begin{array}{l}\text { Oyun ya da maç gibi ortamda basamaklamanın oluştuğu öğretim } \\
\text { tasarımıdır. Örneğin, basketbolda 3'e } 3 \text { oyunda pasif olan } \\
\text { savunmanın aktif hale getirilmesi gibi. }\end{array}$ \\
\hline $\begin{array}{l}\text { Uygulamada } \\
\text { lyileştirme (Ui) }\end{array}$ & $\begin{array}{l}\text { Maç/oyun sırasında iyileştirmeyle ilgili öğretim tasarımının ortama } \\
\text { dâhil edilmesidir. Örneğin, hentbolda 3'e 3 oyunda pas almadan } \\
\text { önce boş alana hareket etmeyen oyuncular için sahanın farklı } \\
\text { yerlerine renkli noktalar koyup her pas sonrası örencilerin bu } \\
\text { noktalardan birine koşmasını istemek. }\end{array}$ \\
\hline $\begin{array}{l}\text { Maç/Oyun } \\
\text { Uygulaması (MU) }\end{array}$ & $\begin{array}{l}\text { Önceki öğretim tasarımın belirtilmediği, bir öğretimsel odağın } \\
\text { olmadığı maç ya da oyun performansıdır. Örneğin; 4'e 4 maç } \\
\text { yapmak gibi. }\end{array}$ \\
\hline $\begin{array}{l}\text { Uygulamada } \\
\text { Değerlendirme (UD) }\end{array}$ & $\begin{array}{l}\text { Maç ya da oyun performansı olmadan uygulamanın } \\
\text { değerlendirildiği öğretim tasarımıdır. Örneğin, teniste öğrencilerin } \\
\text { bir topu oyunda tutarak üst üste yaptıkları maksimum pas sayısını } \\
\text { saymak gibi. }\end{array}$ \\
\hline
\end{tabular}

\section{Öğretim Tasarımı Geliştirme Derinliğinin Ölçülmesi}

Katılımcıların ÖAB derinliğini ya da yeterliğini ölçmek için ÖAB indeks skoru hesaplanmaktadır. Ward ve arkadaşları (2017) tarafından belirlenen ve geçerliği sağlanan formülü. ÖAB indeks skorunu belirlemek için bu çalışmada kullanılmıştır. Alan yazındaki güncel çalışmalar bu formülün öğretim tasarımı geliştirme becerisinin ölçülmesinde etkili olduğunu teyit etmektedir (Dervent, Ward, Devrilmez, \& Tsuda, 2018; He, Ward, Wang, \& Li, 2017; Tsuda, Devrilmez, Dervent, \& Ward, 2017). Indeks skoru sürekli değişkendir ve skorların birbiri ile karşılaştırılmasına olanak sağlamaktadır.

Bu çalışmada katılımcıların ÖAB düzeyinin yeterli olması ya da derin olarak kabul edilebilmesi için indeks skorunun 3.0 ve üzeri olması kriter olarak belirlenmiştir. Belirlenen kriterin, yakın zamanda yapılan çalışmalarda ÖAB'nin ölçülmesi için geçerli ve kullanılabilir olduğu kanıtlanmıştır (Dervent vd., 2018; Ward vd., 2018). İçerik haritasının kodlanması sonucunda indeks skorunun 3.0 ve üzeri olması, katıımcının kategorilerden bir bilgilendirme kategorisi yanı sıra diğer kategorilerden en az üç öğretim tasarımı kullandığını gösterir. Örneğin, bir beden eğitimi öğretmeni badmintonda smaç vuruşunu öğretirken öğretim tasarımı geliştirmesi; a) Smaç vuruşunun pozisyonunun (gölge) gösterilmesi (bilgilendirme), b) Yakın mesafeden top besleme (basamaklama), c) uzak mesafeden top besleme (basamaklama), d)Smaç vuruşunda raketin aşağı doğru kapatılması için ağır raketle çalışma (İyileştirme). Bu durumda beden eğitimi öğretmeninin ÖAB indeks skoru, bir bilgilendirme ve iki basamaklama ve bir iyileştirme öğretim tasarımları kullanması nedeniyle 3.0 olarak belirlenir.

\section{Kodlayıcı Protokolü ve Gözlemciler arası Tutarlılık}

Bu çalışmanın içerik haritalarını üç kodlayıcı gerçekleştirmiştir. Kodlayıcılar, verileri kodlamadan önce üç aşamalı süreç ile kodlama eğitimi almışlardır. Kodlama eğitimi Dervent, Tsuda, Devrilmez ve Ward'ın (2016) öğretim tasarımı geliştirme kılavuzunda belirtilen süreçleri içermektedir. Birinci aşamada kodlayıcılara öğretim tasarımı geliştirme kategorileri açıklanmış ve örneklerle anlaşıırlığın arttırılması sağlanmıştır. Kodlayıcılar bu kategorileri birbirleriyle tartışmış ve örnekleri farklılaştırarak kategorileri daha iyi anlamaya çalışmışlardır. Kodlayıcılar kategorileri tam olarak içselleştirdiklerini ifade ettiklerinde kendilerine 22 öğretim tasarımı ve bunların karşılığına gelecek kodlar verilmiştir. 
Kodlayıcılardan bu öğretim tasarımları ile kodları eşleştirmeleri istenmiştir. Diğer aşamaya geçmek için kodlayıcılar bu eşleştirmeyi \%100 doğru yapmaları gerekmektedir. Katılımcılar \%100 eşleştirme yaptıklarında ikinci aşamaya geçmişlerdir. İinci aşamada kodlayıcılara 26 öğretim tasarımı verilmiş ve bunları yine \%100 doğrulukla açıklamaları istenmiştir. Gerekli doğruluk oranı sağlandığında son aşamaya geçilmiştir. Üçüncü aşamada kodlayıcılar videolar, ders planları ve içerik haritalarında yer alan 104 öğretim tasarımını kodlamışlardır. Bu son aşamanın geçilmesi ve eğitimin tamamlanabilmesi için kodlayıcıların toplam öğretim tasarımlarının \%95'inde tutarlı olmaları gerekmektedir. Son aşamada kodlayıcılar başarılı olmuşlar ve eğitimi tamamlamışlardır. Kodlayıcılar arası tutarlııı̆ı kontrol etmek için toplam içerik haritalarının \%33'ü $(\mathrm{N}=116 / 3=38)$ kodlayıcılar tarafından kodlanmış ve tutarlılık .98 olarak belirlenmiştir.

\section{Öğretim Programları ve Ders Müfredatlarının Tutarlılı̆ı}

Çalışmada yer alan üç grubun uyguladıkları program ile ders müfredatlarının tutarlı olup olmadığı kontrol edilmiştir. Beden eğitimi öğretmenliği bölümü derslerinin tamamı, spor yöneticiliği bölümünün \%60'ını ve antrenörlük bölümü derslerinin \%65'i çalışmanın ilk ve ikinci yazarları tarafından doğrudan gözlemlenmiştir. Üç grubun ders müfredatlarında belirtilen içerikler ile hafta hafta uygulamaları arasındaki tutarlıık kontrol edilmiştir. Bu doğrultuda öğretim elemanlarından ders müfredatları istenmiş ve yürüttükleri dersler gözlenerek kontrol edilmiştir. Öğretim elemanları haftalık ders müfredatına uygun ve içeriklerle tutarlı derslerini yürütmüşlerdir. Ayrıca içerikte belirtilenler ile uygulamalarda kullanılan pedagojik adımlar kontrol edilmiştir. Öğretim elemanlarının kullandığı öğretim ile ders müfredatlarının içeriği tutarlı bulunmuştur. Son olarak üç grubun öğretim programlarının odaklandığı uygulamalar hakkında karara varımışıı. Ders müfredatları, izlenen ders videoları ve öğretim elemanlarının uygulamaları sonucunda beden eğitimi öğretmenliği bölümünün ÖAB odaklı, antrenörlük bölümünün hem ÖAB hem de GAB'ne vurgu yaptığı ve spor yöneticiliği bölümünün de geleneksel GAB odaklı cimnastik dersi yürüttükleri belirlenmiştir.

GAB ve ÖAB odaklı derslerin işleniş farkının belirtilmesi, çalışmanın amacı, tasarımı ve uygulamaları konusunda açıklayıcı olacaktır. Öğretim programlarında ÖAB odaklı ders işlenmesi, öğretim elemanının dersin öğretim süreci ve uygulamalarda öğretmenlik becerisine odaklanması demektir (Ward 2009). Beden eğitimi öğretmenliği bölümündeki derslerde cimnastik sporuna özgü tekniklerin uygulanmasından ziyade bu tekniklerin nasıl öğretileceği üzerinde durulmuştur. Dersin başında belirlenen teknikler basitten karmaşığa giden öğretim basamaklarının anlaşılması için öğrenciler tarafından kısa süreli olarak uygulanmış, kalan sürede ise öğrenciler bu teknikleri belirledikleri basamaklarla birbirlerine öğretmişlerdir. Her ders sonunda öğrenciler öğretmenlik deneyimleri üzerine yansıtıcı düşünme odaklı tartışma seanslarına dâhil olmuşlardır. Bu seanslar öğretim elemanının rehberliğinde, öğrencilerin sonraki haftalardaki öğretmenlik performanslarını geliştirmeye yönelik yollar aradıkları yaklaşık 15 dakika süren ders sonu toplantılar olarak gerçekleşmiştir. Tartışma seansında öğrencilere verilen geri bildirimler yalnızca öğretmenlik performansını arttırmaya yönelik ifadeleri içermektedir. GAB odaklı ders, öğrencilerin ders müfredatında yer alan tekniklerin uygulaması ve bu teknikleri sergilemedeki performanslarının ölçülmesi ile gerçekleştirilen derstir. Öğretim elemanı teknikleri gösterir ve öğrencilerinden yapmalarını bekler. Derste başarılı olma kriteri belirlenen tekniklerin doğru yapılma düzeyine bağlıdır. GAB ve ÖAB odaklı derste öğretim elemanı dersinin iki bölümde işlemektedir. Dersin başında belirlenen teknikler öğretim elemanı tarafından gösterilmiştir. Öğrenciler teknikleri uygulamış ve gerekli yerlerde öğretim elemanı düzeltme ve geri bildirim vermiştir. Dersin sonuna doğru öğrenciler belirlenen teknikleri uygularken birbirlerine yardım edip hareketlerin uygulamasında birbirlerine düzeltmeler vermişlerdir. Öğrencilerin öğretim 
basamaklamalarını takip etmeleri istenmiş ve öğretim elemanı işlenen teknikler ile ilgili ders sonunda geri bildirim vermiştir.

\section{Veri Analizi}

Grupların analizi için tanımlayıcı istatistik ve gruplar arası farkı belirlemek için tek yönlü ANOVA testi kullanılmıştır. ANOVA testi öncesinde varsayımlar kontrol edilmiştir. Illk olarak bağımsız gözlem varsayımı araştırmacılar tarafından sağlanmıştır. İkinci varsayım, normallik varsayımıdır ve skewness-kurtosis değerleri (-2 ile +2 arası), histogram ve p-p plotlar ile kontrol edilmiştir. Tüm değerler ve grafikler verilerin normal dağılım sağladığını göstermektedir. Son olarak homojenlik varsayımı kontrol etmek için levene's test değerleri kontrol edilmiştir. Grupların homojen dağıldığı test sonuçlarına göre sağlanmıştır ( $p>05$ ). Elde edilen bulgular ANOVA analizinin yapılmasının uygun olduğunu göstermiştir. (Tabachnick, Fidel, \& Ullman, 2007).

\section{Bulgular}

Çalışmada GAB ve ÖAB ortalama değerleri grafik 1 ve grafik 2 de sunulmuştur. Cimnastik GAB testinde toplam 19 soru yer almaktadır.

Grafik 1. Cimnastik Genel Alan Bilgisi Testi Doğru Cevap Yüzdeleri

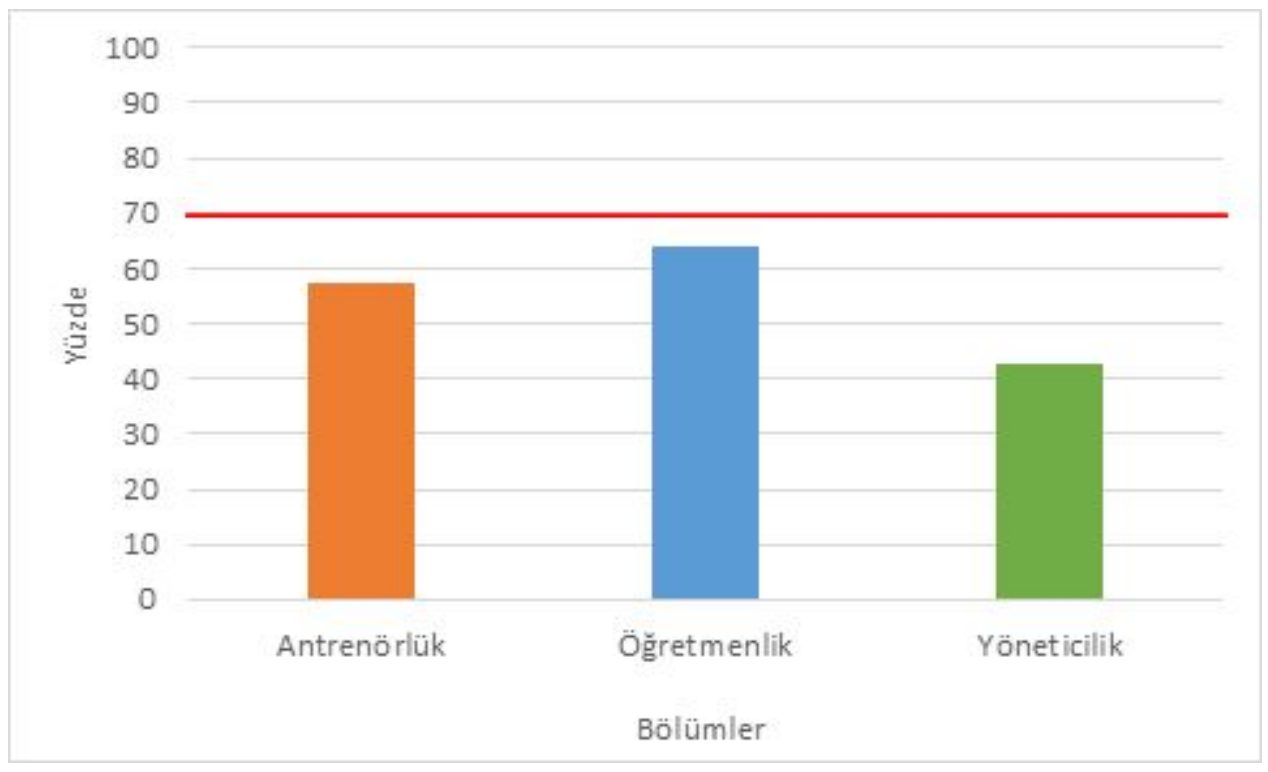

Üç grubun cimnastik GAB ortalama bulgularına göre beden eğitimi öğretmenliği bölümü öğrencilerinin ortalaması 12.19 (\%64.16), antrenörlük bölümü öğrencileri ortalaması 10.91 (\%57.42) ve spor yöneticiliği öğrencilerinin ortalaması 8.14 (\%42.84) olarak belirlenmiştir. Elde edilen bulgular üç gruptaki katıımcıların GAB testinden başarılı olma kriterini (\%70 ve üzeri) sağlayamadığını göstermektedir.

Katılımcıların ÖAB ortalamaları grafik 2'de sunulmuştur. Bulgulara göre beden eğitimi öğretmenliği bölümü öğrencilerinin ÖAB indeks skoru ortalaması 3.70 ( $S S=1.70$ ) olarak bulunmuştur. Bu skor beden eğitimi öğretmenliği öğrencilerinin yeterli ÖAB düzeyine $\left(X^{-}=3.70>3.0\right)$ sahip olduklarını göstermektedir. Antrenörlük bölümü $\left(X^{-}=1.29, \quad S S=1.01\right)$ öğrencileri ise yeterli ÖAB düzeyine 
ulaşamamıştır. Antrenörlük bölümü öğrencileri yeterli olmasa da belirli bir seviye ÖAB'ne sahip oldukları görülmektedir. Ancak spor yöneticiliği bölümü öğrencilerinin cimnastik sporuna yönelik ÖAB düzeyinin olmadığı $\left(X^{-}=.00\right)$ görülmektedir.

Grafik 2. Özelleşmiş Alan Bilgisi Ortalama Skorları

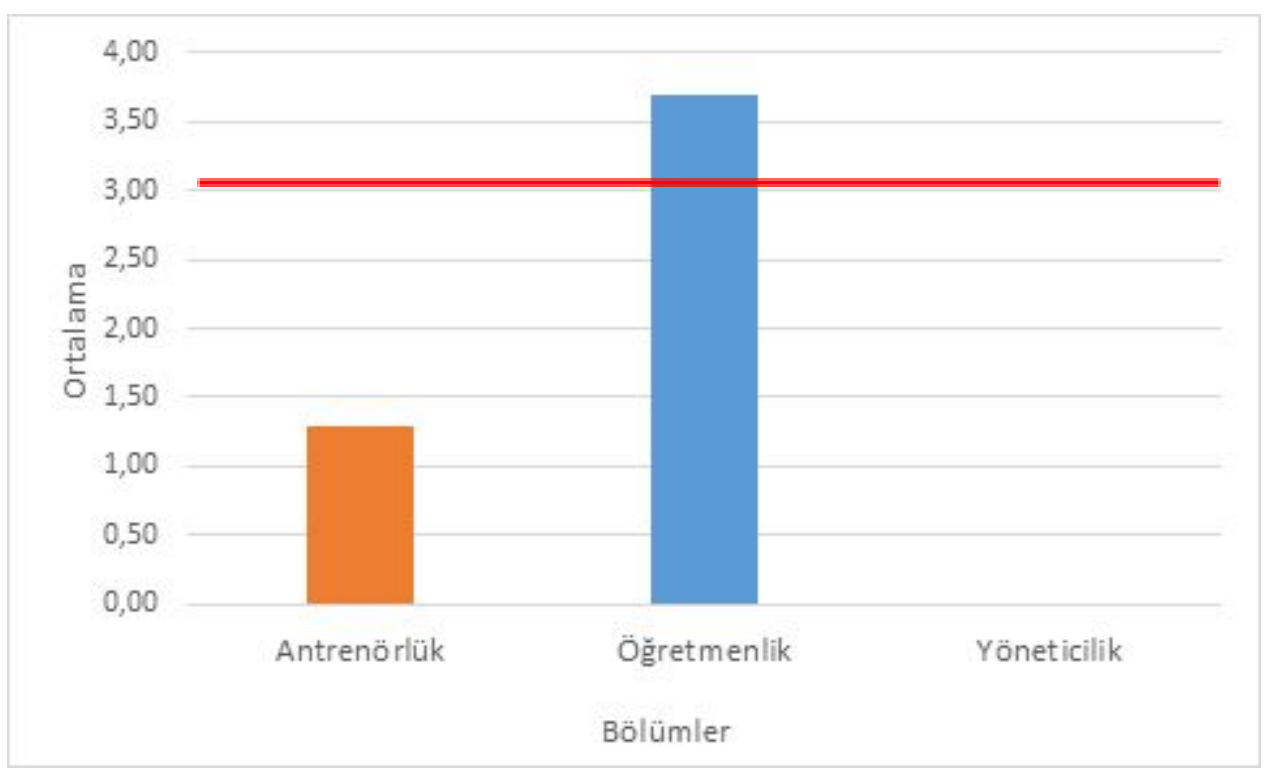

Grupların GAB ve ÖAB düzeylerine göre karşılaştııılığı ANOVA bulguları grafik 3'de verilmiştir. Tabloya göre GAB açısından gruplar arası anlamlı farklıık tespit edilmiştir $\left(F_{(2)}=31.81, p<.05\right)$. Anlamlı farkın nereden kaynaklandığını tespit etmek için bonferonni takip testi kontrol edilmiştir. Teste göre beden eğitimi öğretmenliği ve antrenörlük bölümleri istatistiksel olarak spor yöneticiliği bölümü öğrencilerinden daha iyi bulunmuştur $(p<.05)$. Beden eğitimi öğretmenliği ve antrenörlük bölümleri arasında istatistiksel olarak fark bulunmamıştır ( $p>05$ ).

Tablo 3. Katılımcıların Genel ve Özelleşmiş Alan Bilgisi ANOVA Tablosu

\begin{tabular}{llcccc}
\hline & & df & $X^{-2}$ & F & P \\
\hline Genel alan bilgisi & Gruplar arası & 2 & 171.23 & 31.81 & .00 \\
& Grup içi & 116 & 5.38 & & \\
& Toplam & 118 & & & \\
\hline Özelleşmiş alan bilgisi & Gruplar arası & 2 & 149.59 & 102.05 & .00 \\
& Grup içi & 116 & 1.47 & & \\
& Toplam & 118 & & & \\
\hline
\end{tabular}

ANOVA tablosuna göre grupların ÖAB düzeyleri arasında anlamlı fark bulunmuştur $\left(F_{(2)}=102.05, \mathrm{p}<.05\right)$. Anlamlı fark için kontrol edilen bonferonni testi beden eğitimi öğretmenliği ve antrenörlük bölümlerinin spor yöneticiliği bölümünden istatistiksel olarak daha yüksek ÖAB skoruna sahip 
olduklarını göstermektedir. Ayrıca beden eğitimi öğretmenliği bölümü katılımcılarının ÖAB düzeyi, antrenörlük bölümünün ÖAB düzeyinden anlamlı düzeyde yüksek bulunmuştur ( $p<.05$ ).

\section{Tartışma ve Sonuç}

Bu çalışmanın amacı, beden eğitimi bölümlerindeki öğrencilerin cimnastik alan bilgisi düzeylerinin incelenmesidir. Bulgulara göre çalışmaya katılan üç grubun GAB skorları, beklenen başarı oranını yakalayamamış görünmektedir. Genel eğitim (South Carolina Department of Education [SDE], 2000) ve beden eğitimi (Castelli \& Williams, 2007; Devrilmez, 2016) alanyazınlarında kullanılan bilgi testlerinde başarılı kabul edilme kriteri, testte yer alan toplam soruların en az \%70'inin doğru cevaplanması olarak belirlenmiştir.

Beden eğitimi alanında öğrencilerin takım oyunlarındaki (Capel \& Katene, 2000) ve egzersiz fizyolojisindeki (Martin, 2008) alan bilgisi düzeyleri bilgi testleri ile araştııımış ve çalışmamızla paralel şekilde düşük alan bilgisi tespit edilmiştir. Benzer düşük GAB skorları sağlıkla ilgili fiziksel uygunluk çalışmalarında görülmektedir (Castelli \& Williams, 2007; Ince \& Hunuk, 2013; Santiago, Disch, \& Morales, 2012). Santiago ve arkadaşları (2012) 89 beden eğitimi öğretmeninin sağlıkla ilgili fiziksel uygunluk bilgi düzeylerini ölçmüşlerdir. Bulgulara göre katılımcıların ortalama skoru \%57.6 (<\%70) ile beklenen seviyenin altında bulunmuştur. Düşük GAB bulgularının nedeni olarak beden eğitimi öğretmenliği bölümlerindeki eğitim-öğretim süreci, derslerde odaklanılan alan bilgisi ve verilen derslerin kalitesi vurgulanmaktadır.

Son zamanlarda Rasch modellemesi kullanılarak farklı fiziksel aktivite ve sporlar için GAB testleri geliştirilmiştir (Dervent, Devrilmez, Ince, \& Ward, 2018; Devrilmez, Dervent, Ward, \& Ince, 2019; Devrilmez, Dervent, \& Yoruç Çotuk, 2019; He, Ward, \& Wang, 2018). Dervent ve arkadaşları (2018) yaptıkları çalışmada Futbol GAB testinin geçerlik ve güvenirliğini sağlamışlardır. Çalışmaya katılan beden eğitimi öğretmenliği bölümlerinde futbol dersi almış öğrencilerin futbol GAB düzeyi (\%53.56) düşük bulunmuştur. Voleybol için geliştirilen GAB testi çalışmasında voleybol dersini tamamlamış beden eğitimi öğretmenliği bölümü öğrencilerinin voleybol GAB düzeyi de (\%48.15) beklenen seviyenin altındadır. Beden eğitimi öğretmeni yetiştiren bölümlerindeki fiziksel aktivite ve spor derslerinde GAB'ne daha fazla zaman ayrılmasına rağmen (Ince, Ward, \& Devrilmez, 2012; Ward vd., 2013), dersi tamamlayan öğrenciler düşük GAB skorları elde etmektedir. Düşük GAB skorlarının gerçek nedeni tam olarak bilinmese de beden eğitimi öğretimi bölümlerindeki derslerin kalitesi ve kullanılan öğretim stratejileri bu durumu oluşturduğu söylenebilir (Kirk, 2010). Bunun yanında ulaşılan bulgular ışığında bir spor dalına özgü teknik becerileri uyguluyor olmanın o spora ilişkin GAB düzeyinde artış sağlamadığı söylenebilir.

Araştırmamıza katılan beden eğitimi öğretmenliği bölümü öğrencileri beklenen ÖAB seviyesine ulaşmıştır. Yakın zamanda Ward ve arkadaşları (2018), GAB ve ÖAB odaklı iki grubun ÖAB düzeylerini karşılaştırmıştır. Çalışmada ÖAB odaklı grup beklenen ÖAB seviyesine ulaşmış, ancak GAB odaklı grubun son test sonuçları yeterli ÖAB düzeyini yakalayamamıştır. Dervent ve arkadaşları (2018) beden eğitimi öğretmen adaylarının ÖAB düzeyi değişimini incelemiştir. Çalışmada yer alan katılımcılar öğretmenlik uygulamalarının (staj) ilk döneminde küçük gruplara (6-8 öğrenci), ikinci dönemlerinde ise tüm sınıfa (25-30 öğrenci) çeşitli spor dallarını öğretmişlerdir. Öğretmen adaylarının ÖAB düzeyi küçük gruplara öğretimde yüksek bulunmuştur (bayrak futbolu $X^{-}=6.05$; hentbol $X^{-}=7.81$ ). Aynı katıımcıların tüm sınıfa öğretmiş olsalar dahi ortalama ÖAB düzeyleri artmıştır $\left(X^{-}=11.94\right)$. Bu artışın nedeni benzer sporları farklı bağlamlarda öğretme deneyimine ve öğretmen yetiştirme 
programlarındaki ÖAB odaklı eğitimlerine devam ediyor olmaları olabilir (Higginson \& Ward, 2018; Ward vd., 2018).

Spor yöneticiliği ve antrenörlük bölümü katılımcılarının ÖAB skorları beklenen seviyenin altında bulunmuştur. Ward ve arkadaşlarının (2018) GAB odaklı grubun bulguları çalışmamızla benzerlik göstermektedir. Ayrıca Iserbyt ve Coolkens (2018) yaptıkları araştırmada 18 beden eğitimi öğretmen adayının basketbol ve parkur (bir kişinin koşmak, zıplamak gibi çeşitli istasyonları en kısa sürede tamamlamak için çabaladığı bireysel motor aktivite) ÖAB derinliğini incelemişlerdir. Bulgulara göre her iki fiziksel aktivite ve spor dersinin sonunda öğretmen adaylarının geliştirdikleri öğretim tasarımları sayısal olarak artmış ya da uygulama becerileri gelişmiş olsa da katıımcılar beklenen ÖAB düzeyine ulaşamamışlardır.

Sonuç olarak GAB odaklı ders müfredatlarına ve uygulamalarına sahip olmalarına rağmen beden eğitimi öğretmen adaylarının GAB düzeyi beklenenin altında bulunmuştur. Bunun nedeni ders içeriklerinin teknik odaklı çalışmalar, maçlar ya da seriler ve koreografiler içermesi ayrıca derslerin başarı kriterinin çoğunlukla ilgili spor dalına özgü teknik becerilerin başarılı performansına bağlı olması olabilir. Bu nedenle GAB odaklı derslerin tekrar gözden geçirilmesi önerilmektedir. Güncel beden eğitimi ve spor öğretmenliği lisans programlarında ÖAB'ne vurgu yapılmaya başlanması her ne kadar önemli bir adım olsa da bu programlarda fiziksel aktivite ve spor derslerini yürüten öğretim elemanlarının ders işleyişlerini beceri uygulama ve performans ağırlıklı olarak gerçekleştirdikleri düşünülmektedir. Derslerini ÖAB odaklı şekilde gören beden eğitimi öğretmenliği bölümü öğrencileri etkili öğretim için yeterli ÖAB düzeyine sahipken antrenörlük ve spor yöneticiliği bölümü öğrencileri gereken seviyeye erişememişlerdir. Bulgular, fiziksel aktivite ve spor derslerinin ÖAB odaklı olarak işlendiğinde öğrencilerin ÖAB düzeylerini gelişimini sağladığını göstermektedir. Bu ayrıca spor dalına özgü becerileri uygulamanın (performans) o becerilerin öğretiminde gerekli ÖAB'ne katkı yapmadığını da göstermektedir. Bu nedenle; fiziksel aktivite ve spor derslerinde beden eğitimi ve spor öğretmenliği bölümlerindeki beden eğitimi öğretmen adaylarının etkili öğretmenlik için gerek duydukları ÖAB'nin ayrıca ve özel olarak öğretilmesi önerilir.

\section{Kaynakça}

Atkins, M., \& Brown, G. (2002). Effective teaching in higher education. London: Routledge

Ball, D.L., Thames, M.H., \& Phelps, G. (2008). Content knowledge for teaching: What makes it special? Journal of Teacher Education, 59(5), 389-408.

Capel, S., \& Katene, W. (2000). Secondary PGCE PE students' perceptions of their subject knowledge. European Physical Education Review, 6(1), 46-70.

Castelli D., Williams L. (2007). Health-related fitness and physical education teachers' content knowledge. Journal of Teaching in Physical Education, 26, 3-19.

Dervent, F., Ward, P., Devrilmez, E., \& Tsuda, E. (2018). Transfer of content development across practica in physical education teacher education. Journal of Teaching in Physical Education, 37(4), 330-339.

Dervent, F., Tsuda, E., Devrilmez, E., \& Ward, P. (2016). Content development coding assessment manual. Version 2.1. Erişim adresi: https://u.osu.edu/ltpe/

Devrilmez, E., Dervent, F., \& Yoruç Çotuk., M. (2019). Validation of volleyball common content knowledge test. International Journal of Sport, Exercise \& Training Sciences, 5(1), 31-39.

Devrilmez, E., Dervent, F., Ward, P., \& Ince, M.L. (2019). A test of common content knowledge for gymnastics: A Rasch analysis. European Physical Education Review, 25(2), 512-523.

DPT., T.C., 2000, Başbakanlık Devlet Planlama Teşkilatı Müsteşarlığı Sekizinci Beş Yıllık Kalkınma Planı, 
"Beden Eğitimi, Spor ve Istanbul Olimpiyatları" özel ihtisas komisyon raporu, Yayın No: 2513-ÖiK: 530, S: 37.38, Ankara.

Educational Testing Services. (2012). Research sections to be added to some Praxis computer delivered tests. Erişim adresi: http://www.ets.org/praxis/important_update/ research_sections.

Ellis, R. (2018). Quality assurance for university teaching: Issues and approaches. In Handbook of Quality Assurance for University Teaching (pp. 21-36). London: Routledge.

Fraenkel, J.R., Wallen, N.E., \& Hyun, H.H. (2012). Internal validity. How to design an evaluate research in education. New York: McGraw-Hill, 166-83.

Grossman, P.L. (1990). The making of a teacher: Teacher knowledge and teacher education. Teachers College Press, Teachers College, Columbia University.

Hastie, P.A., \& Vlaisavljevic, N. (1999). The relationship between subject-matter expertise and accountability in instructional tasks. Journal of Teaching in Physical Education, 19(1), 22-33.

He, Y., Ward, P., Wang, X., \& Li, W. (2017). Chinese physical education teachers' specialized content knowledge of soccer. Research Quarterly for Exercise and Sport Supplement, 88, A4.

He, Y., Ward, P., \& Wang, X. (2018). Validation of a common content knowledge test for soccer. Journal of Teaching in Physical Education, 37(4), 407-412.

Higginson, K., \& Ward, P. (2018). Do this, not that: important pedagogies for secondary school physical education teachers. Journal of Physical Education, Recreation \& Dance, 89(7), 23-27.

Ince M.L., Hünük D. (2013). Experienced physical education teachers' health-related fitness knowledge level and knowledge internalization processes. Education and Science, 38(168), 304-317.

Ince, M.L., Ward, P., \& Devrilmez, E. (2012). Common content knowledge and specialized content knowledge on physical activity and sport courses in Turkish PETE programs. Oral session presented at 12th International Sport Science Congress, Denizli, Turkey.

Iserbyt, P., \& Coolkens, R. (2018). Content development as a function of content knowledge courses in preservice physical education teachers. Journal of Physical Education and Sport, 18(4), 2440-2446.

Iserbyt, P., Theys, L., Ward, P., \& Charlier, N. (2017). The effect of a specialized content knowledge workshop on teaching and learning basic life support in elementary school: A cluster randomized controlled trial. Resuscitation, 112, 17-21.

Iserbyt, P., Ward, P., \& Coolkens, R. (2018). The effect of specialised content knowledge on pedagogical content knowledge and student learning. In AIESEP, Location: Edinburgh.

Iserbyt P., Ward P., Li W. (2017). Effects of improved content knowledge on pedagogical content knowledge and student performance in physical education. Physical Education and Sport Pedagogy, 22, 71-78.

Iserbyt P., Ward P., Martens J. (2015). The Influence of content knowledge on teaching and learning in traditional and sport education contexts: an exploratory study. Physical Education and Sport Pedagogy, 21(5), 539-556

Kim, I. (2016). Exploring changes to a teacher's teaching practices and student learning through volleyball content knowledge workshop. European Physical Education Review, 22(2),225-242

Kim, I., Ward, P., Sinelnikov, O., Ko, B., Iserbyt, P., Li, W., \& Curtner-Smith, M. (2018). The influence of content knowledge on pedagogical content knowledge: An evidence-based practice for physical education. Journal of Teaching in Physical Education, 37(2), 133-143.

Kirk, D. (2010). Physical Education Futures. London: Routledge.

Launder, A. \& Piltz, W. (2013). Play practice: Engaging and developing skilled players from beginner to elite. Champaign, IL: Human Kinetics. 
Marsh, P. (1982). The choice between equity and debt: An empirical study. The Journal of Finance, 37(1), 121-144.

Mitchell, S., Oslin, J., \& Griffin, L. (2013). Teaching sport concepts and skills: A tactical games approach for ages 7 to 18. Champaign, IL: Human Kinetics.

M.E.B. (2017). Öğretmenlik Mesleği Genel Yeterlilikleri Erişim adresi: https://oygm.meb.gov.tr/ meb_iys_dosyalar/2017_12/11115355.

Rink, J. (1979). Development of a system for the observation of content development in physical education. Unpublished doctoral dissertation. The Ohio State University, Ohio, USA.

Rovegno, I. (1993). Content-knowledge acquisition during undergraduate teacher education: Overcoming cultural templates and learning through practice. American Educational Research Journal, 30(3), 611-642.

Santiago, J.A., Disch, J.G., \& Morales, J. (2012). Elementary physical education teachers' content knowledge of physical activity and health-related fitness. Physical Educator, 69(4), 395-412.

SHAPE America - Society of Health and Physical Educators. (2017). National standards for initial physical education teacher education. Erişim adresi: http://www.shapeamerica.org/ accreditation/upload/2017- SHAPE-America-Initial PETE-Standards.pdf.

Shulman, L.S. (1986). Those who understand: Knowledge growth in teaching. Educational researcher, 15(2), 4-14.

Shulman, L.S. (1987). Knowledge and teaching: Foundations of the new reform. Harvard Educational Review, 57(1), 1-23.

Siedentop, D. (2002). Sport education: A retrospective. Journal of Teaching in Physical Education, 21(4), 409-418.

Sinelnikov, O.A., Kim, I., Ward, P., Curtner-Smith, M., \&Li, W. (2016). Changing beginning teachers' content knowledge and its effects on student learning. Physical Education and Sport Pedagogy, 21(4), 425-440.

South Carolina Department of Education. (2000). South Carolina physical education curriculum standards. Columbia, SC: South Carolina Department of Education.

Tabachnick, B.G., Fidell, L.S., \& Ullman, J.B. (2007). Using multivariate statistics. Boston, MA: Pearson.

Tanışlı, D. (2013). Illköğretim matematik öğretmeni adaylarının pedagojik alan bilgisi bağlamında sorgulama becerileri ve öğrenci bilgileri. Eğitim ve Bilim, 38(169), 80-95.

Tsuda, E., Devrilmez, E., Dervent, F., \& Ward, P. (2017). Differences in content knowledge between those who learned performing and teaching. Research Quarterly for Exercise and Sport Supplement, 88, A4.

Turgut, M., Gökyürek, B., \& Yenel, İ. F. (2004). Beden eğitimi ve spor yüksekokullarındaki antrenörlük eğitimi ve spor yöneticiliği bölümlerinde öğrenim gören öğrencilerin bu bölümleri seçme nedenleri ve beklentileri üzerine bir araştırma. Ahi Evran Üniversitesi Kırşehir Eğitim Fakültesi Dergisi, 5(1), 91-99.

Ward, P. (2009). "Content Matters: Knowledge that Alters Teaching." In Historic Traditions and Future Directions of Research on Teaching and Teacher Education in Physical Education, edited by L. Housner, M. Metzler, P. Schempp, and T. Templin, 345 -356. Morgantown, WV: Fitness Information Technology.

Ward, P., \& Ayvazo, S. (2016). Pedagogical content knowledge: Conceptions and findings in physical education. Journal of Teaching in Physical Education, 35, 194-207.

Ward, P., Dervent, F., Lee, Y.S., Ko, B., Kim, I., \& Tao, W. (2017). Using content maps to measure content development in physical education: Validation and application. Journal of Teaching in Physical Education, 36, 20-31. doi:10.1123/jtpe.2016-0059. 
Ward, P., Kim, I., Ko, B., \&Li, W. (2015). Effects of improving teachers' content knowledge on teaching and student learning in physical education. Research Quarterly for Exercise and Sport, 86 (2), 130-139.

Ward, P., Tsuda, E., Dervent, F., \& Devrilmez, E. (2018). Differences in the content knowledge of those taught to teach and those taught to play. Journal of Teaching in Physical Education, 37(1), 59-68.

YÖK. (1998). Eğitim Fakülteleri Öğretmen Yetiştirme Programlarının Yeniden Düzenlenmesi. http://www.yok.gov.tr/egitim/ogretmen/ogretmen_yetistirme_lisans/rapor.doc.

Yüksek Öğretim Kurumu (YÖK) (2018). Beden eğitimi ve spor öğretmenliği lisans programı. Erişim adresi: https://www.yok.gov.tr/Documents/Kurumsal/eğitim_öğretim_dairesi/YeniÖğretmen Yetiştirme- Lisans Programları/Beden_Eğitimi_ve_Spor_öğretmenliği_Lisans_Programı.pdf. 